\title{
Talent Management through "Trainee Programmes" \\ Conceptual Preliminaries and Research-Based Advice on \\ The Design of Corporate Educational Programmes for University Graduates
}

\author{
Prof. Norbert Thom \\ Institute for Organisation and \\ Human Resource Management (IOP) \\ University of Bern - Switzerland
}

\begin{abstract}
Studies suggest that HR managers worldwide perceive talent management as a field of managerial activity that is of crucial importance, but rather badly handled in actual practice. So-called "trainee" or "graduate programmes" - on-the-job training programmes for university graduates - offer an excellent path towards improvement here, but so far have received surprisingly scant attention outside German-speaking Europe. Drawing on many years of research and close relations with HR practitioners, the author hopes with the present paper to stimulate an interest in such programmes among HR specialists in Poland and, as the case may be, further regions of Eastern Europe, and to provide an overview of the essential dos and don'ts in implementing them.
\end{abstract}

Key words: HR Management, HR Development, Talent Management, Training, Graduates

\section{Introduction}

Few issues in HR management have seen such a boost in significance in recent times as talent management has. In 2010, Boston Consulting Group, in collaboration with the World Federation of Personnel Management Associations WFPMA, conducted a survey among $5561 \mathrm{HR}$ specialists around the globe, asking which fields of activity they expected to grow in importance in the future ("future importance") and how well they thought they were currently handled ("current capability"; cf. [1]). Regarding future importance, "managing talent" was rated exceedingly high in the survey. At the same time, current capability was assessed as particularly low. From this striking imbalance, the authors of the study derived a "strong need to act". A follow-up study of 2011, covering 2039 HR managers in 35 European countries, came to a similar conclusion (cf. [2], [6]).

Drawing on many years of research and close relations with HR practitioners, the author hopes to show in the present paper that in German-speaking Europe, vast amounts of knowledge and experience have been gathered in the more specific area of fostering talented young university graduates in so-called "trainee" or "graduate programmes". He would therefore venture that the somewhat unsettling outcome of the BCG/WFPMA study surely must be qualified for the German-speaking world in view of what has been achieved there: the claim is that when it comes to talent management by means of trainee programmes, its future importance has been very well recognised, and the current capability with which organisations address the issue is quite considerable.

* This article was submitted in November 2018, and accepted for publishing in December 2018. 
The author is among those who firmly believe in the potential of trainee programmes as a talent management instrument, and he thinks that companies in all regions of Europe and the world could and should benefit from them. The present article, accordingly, is intended to stimulate an interest in trainee programmes among HR specialists outside the German-speaking world, and to provide an overview of the dos and don'ts in implementing such programmes.

Before dealing more closely with trainee programmes as a talent management tool, a number of preliminary remarks on the concepts of talent and talent management are requisite.

\section{Talent and Talent Management: Conceptual Preliminaries}

In antiquity, the term talent referred to various units of weight (usually of precious metals) and corresponding units of monetary value. The concept thus bore connotations of "value" and "valuable" from the outset; there was also a further connotation of "trust" in said (monetary) value. A new figurative meaning appeared in the $15^{\text {th }}$ century: probably deriving from its "monetary value" sense, talent came to be used to refer to a special aptitude or giftedness in a certain field of human activity. Later on, the concept expanded further, so that talent could now also refer to a person possessing an aptitude of the mentioned kind, or indeed - a very common usage today - as a generic term to whole groups of talented people.

In the narrower sense the term assumes, in the context of HR management, one feature of talented employees, i.e. they tend to have gone through higher education. This, however, does not need to always be of an academic nature - just think of celebrity chefs or particularly gifted craftspeople. Furthermore, talented workers are taken to be highly motivated and to love challenging tasks. They have an incessant craving for continued professional training, and they satisfy this need whenever they can. Where these kinds of assets are crowned with highly developed social skills (e.g. with regard to communication and cooperation), such people are viewed as particularly talented. In this case, the talented person has a socially skilled manner of interacting with colleagues, superiors and with people outside the organisation (e.g. customers). From the employer's point of view, one might say in short then that a talented person possesses certain key skills that are particularly useful and important for the company's continued favourable development and overall success.

Talent management is defined by the authors of the mentioned BCG/WFPMA study as concerned with "attracting, developing and retaining all individuals with high potential - regardless of whether they are managers, specialists or individual contributors - across all levels of the organization" ([1]). Experts in the field generally like to speak of a "high potential" of people with talent. In the European management literature, the concept of "high potential" is sometimes used more narrowly for those who not only show potential for development, but who are also at a point in their current position where they have attained their maximum level of performance (cf. [9]). In any case, talented young employees are supposed to have or to develop towards such a status of high potential.

Today, talent management has attained a firm position within HR management teaching and research. In a current anthology on the topic, talent management is described as "focused on the core process of HR management that comprises everything from recruitment to evaluation and development all the way down to retention management" ([4, p. 15]; our translation). In the understanding of the present author and 
his research collaborators (e.g. [11], [12]), talent management takes the shape of a cross-domain process within the company's overall HR management scheme. Talent management is a task shared between line managers and HR management specialists. Both will need to cooperate when it comes to attracting talented people, introducing them to the organisation, assessing their performance and potential, developing their skills and retaining their capability and willingness to perform within the company.

On this view, the core process of talent management (devoted to attraction, introduction, assessment, development and retention of talent) is affected by five overarching functions of HR management:

1- Strategic HR Management: Strategic HR management is concerned with adjusting the HR strategy (how much staff with what skills will we require in the future?) to the overall company strategy (on which markets do we want to compete, using what kind of competitive strategy?). This will clarify not only what kind of talent will be needed where and when, but also what objectives the organisation can achieve through talent in the first place.

2- Organisation of HR Management: Who (line managers, own and external HR specialists) is assigned with which tasks in talent management, with what capacities (decision-making and other authority) and responsibilities? How to organise the sub-processes of talent management?

3- HR Planning: HR planning must be coordinated with corporate planning in other domains (e.g. sales, production and financial planning). This part of operational planning specifies personnel requirements in both quantitative and qualitative terms and clarifies what kind of talent management the company can afford.

4- HR Marketing: The task here is to increase the employer's attractiveness on the relevant labour markets. For this purpose, the company must know the needs of target groups (in this case, talented jobseekers) and must offer appropriate incentives.

5- HR Controlling: This comprises continual monitoring of the key figures that are relevant in the tailoring of all activities to the objectives pursued. Certainly relevant to talent management are, for instance, figures on the duration of stay in specific positions, results of performance assessment, job satisfaction, and activities and advances in further education.

With this, we have sufficiently outlined the framework within which the talent management core process is situated. In the next section, we briefly discuss what trainee programmes actually are and what they aim at, before going on to identify some of the crucial design features they must have if they are to succeed as a talent management tool.

\section{Talent Management through Trainee Programmes}

In Germany, the first trainee programmes for graduates (henceforth: $\operatorname{Tr} P r$ ) in business administration and economics were introduced immediately after the Second World War. Today, such programmes are standard in many companies in German-speaking Europe, while the target group has been enlarged to include engineers, lawyers or scientists with business proclivities. Manfred Becker, the best known German author on HR development, provides the following brief characterisation: “...university graduates are systematically introduced to their new environment, to tasks and the corporate culture. Trainee programmes aim to make things easier for graduates at the start of their working lives. To this end, trainees 
proceed through various positions within the company. In addition, they are subjected to supplementary educational measures. Trainee programmes last from 6 to 24 months" ([3, p. 560]).

The author of the present paper has continuously observed and, together with his collaborators, done extensive research on $\operatorname{TrPr}$ since the 1970 s. One of his own early definitions of $\operatorname{TrPr}$ specified that they were "supposed to allow a selected circle of university graduates to receive basic training preparing for future management positions, to become clearer about their capabilities and interests, to establish personal relations and to become familiar with the corporate structure and culture of an organisation" ([8]).

Today, talk of a "select circle" is certainly still appropriate in connection with attractive employers, where large numbers of candidates apply for any available programme position. Often, complex procedures (e.g. assessment centres) are used in selecting the most suitable individuals.

Other parts of the definition, however, require modification from a contemporary viewpoint. "Future management positions", for one thing, must be made more precise: while former trainees continue to be candidates for line management careers, and in some companies have indeed reached top management positions, many of today's employers also offer opportunities for technical specialists or project managers as an alternative to classical management careers (cf. [7], which provides examples). Furthermore, research suggests that the learning objectives as sketched out in the above definition of Thom ([8, p. 218]) should be spelled out and completed as follows:

1- The educational objective is still fundamental. After completion of the programme, trainees should be prepared for a job at management assistant level that is adequate to their formal education (e.g. junior controller, product manager, HR manager).

2- Also an informational objective remains firmly in place. Trainees are supposed to get to know the company and to become more reassured about their own personal performance capacities and their preferences regarding the subsequent stages of their professional lives. Employers for their part hope to learn as much as possible about the abilities and interests of each individual trainee.

3- The objective of integration amounts to the trainee's deeper understanding and internalizing of the corporate culture - or, more precisely, of the system of core values to which each of the visited departments subscribes.

4- The image objective captures the employer's aim to attract as many excellently qualified applicants as possible. Employer's attractiveness is to be raised on the talent labour market (i.e. particularly among advanced students on relevant university courses).

TrPr are a costly matter; from an accountancy viewpoint, they are an investment. Accordingly, an adequate return in the form of work in the employer's service is expected after the TrPr. Thus, pursuing a sustainability objective, the employer strives to make trainees stay in the company for a certain amount of time (e.g. three years) after completion of the programme.

By means of trainee programmes, employers basically aim to establish a corporate pool of qualified and highly motivated young professionals. On the basis that they possess the characteristic features of talented workers mentioned above, former trainees may go on to enjoy continued special fostering and be promoted to positions with more complex task profiles. On the classical view in German-speaking Europe, 
however, no one is talented forever just because they have participated in a corresponding programme at some point. New decisions must be made after every stage of testing the candidate's worth as to whether they are still part - and still want to be part - of the talent pool. At this point, the obvious question arises as to how the objectives, on the part of both trainees and employers just discussed, can be achieved to the best possible degree. As the initial claim of this paper has it, a considerable base of knowledge and experience has accumulated in the German-speaking world in this regard. In academic research, great amounts of empirical data have been collected and analysed. Two research institutes, with which the present author is affiliated, for instance, have carried out six studies on TrPr in Germany and another six in Switzerland. In the course of this work, a wide range of valuable insights regarding the actual design of such programmes has been won (cf. [9], [10]). In particular, certain long-term tendencies (relating, for instance, to the duration of $\mathrm{TrPr}$, their customisation versus standardisation, the importance of stays abroad, different programme types, or recurrent problems in $\mathrm{TrPr}$ implementation) have been identified. Shortage of time on the part of trainees' superiors is one striking and very serious problem in designing TrPr. Over the course of the programme, trainees shift between various departments (e.g. sales, accounting, HR). An implicit presumption here is that the various departments' superiors have enough time to impart the necessary practical and theoretical knowledge to the trainees. However, in ten of the twelve mentioned empirical studies in Germany and Switzerland, lack of time on the part of superiors for teaching and supervision turned out to be the greatest obstacle to an effective and efficient programme. Insufficient time resources of superiors, however, jeopardise several of the objectives of $\operatorname{TrPr}$ as laid out above. This is evident with regard to the educational objective; but also familiarisation with values (objective of integration) may be hampered, along with other aims. In a series of workshops with $\operatorname{TrPr}$ directors organised by the author, one important reason for time shortage was identified: in both the job profiles (job descriptions) and the annual objectives of superiors, the objectives of TrPr tend to rank only very low or even do not figure at all. This simple circumstance seriously endangers the success of $\operatorname{TrPr}$.

The last large-scale research project on $\operatorname{TrPr}$ supervised by the author of the article was completed in 2012 at the University of Bern's Institute for Organisation and Human Resource Management (IOP) and resulted in the monograph of Nesemann ([5]). This book and all its contents so far have been published in Germany only; our presentation of the principal results in the remaining paragraphs represents their first publication in English. The project, whose methodology and outlook derived from a long series of preceding studies, started out from a very wide-ranging and varied database. After systematic selection from 552 providers of TrPr in German-speaking Europe, 136 (88 German, 35 Swiss, 13 Austrian) were taken into account. All of them offered TrPr with the following minimal set of features:

1- Trainees are recruited among graduates from universities or universities of applied science, mostly in business administration and economics, but also in law, engineering, computer and natural science.

2- The programme consists of planned and well-organised procedures with an overall didactical structure. Trainees enjoy training both on the job and parallel to it, engage in project work, and shift between multiple training positions (job rotation). 
3- Programme duration ranges from 6 to 24 months.

4- There are several participants in the programme at any time (the programme does not amount to a mere development measure for single individuals).

After filtering out the very few defective questionnaires, 130 cases (providers of $\operatorname{TrPr}$ ) were finally analysed (cf. [5, pp. 125-128]). Before going into hypotheses and results, a bit of statistical background: firstly, companies from the services sector (banking, trade, insurance) were much more numerous in the sample than employers in the industrial sector (63\% versus 37\%). Secondly, the $\operatorname{Tr} \operatorname{Pr}$ under analysis had an average length of about 18 months (arithmetic mean: 17.8; mode: 18 months). Third, the trainees proceeded through four to five training positions (arithmetic mean: 5.2 ; mode: 4 ).

Based on an in-depth analysis of both the existing literature and 12 relevant earlier studies, and taking into account the outcomes of 30 workshops with HR managers on the topic of $\operatorname{TrPr}$ and HR development that the author had organised together with Staufenbiel Institute, Cologne/Germany, a series of hypotheses were derived and tested against the database. Statistical analysis rested on two regression techniques (ordinary least square regression and robust regression). Here are the most important hypotheses that were confirmed by the study:

1- The amount of time spent by trainees' direct superiors on the $\operatorname{Tr} P r$ as a whole has a positive impact on (a) the objective of integration and (b) on the technical educational objective.

2- A visible effort on the part of the company's top management in favour of TrPr adds to a positive internal image of TrPr.

3- A mentoring programme within TrPr may contribute to a positive external image of TrPr.

4- Project work in the course of TrPr has a positive impact on (a) the objective of integration, (b) the technical educational objective of $\operatorname{Tr} \operatorname{Pr}$ (technical training) and (c) the methodological educational objective of $\operatorname{Tr} \operatorname{Pr}$ (training in methodology).

5- Stays abroad enables trainees to acquire intercultural competences as part of the educational objective of $\operatorname{Tr} P r$.

6- Integrating $\operatorname{TrPr}$ within corporate HR development is conducive to retaining trainees in the company for a prolonged period of time after completion of the $\operatorname{TrPr}$, and thus to achieving a sustainability objective. These results call for a number of explanatory comments:

- On 1a: The establishment of good relations between trainees and the people in their surroundings is an important indicator of successful integration of them. This will also ensure that trainees become familiar with formal and informal networks and power structures (the prevailing "rules of the game"; cf. [5, p. 51]). Inclusion in informal networks makes it easier to find allies and to build coalitions ([5, p. 52]).

- On 1b: The aim is also to deepen and expand trainees' technical competences. "Deepening" here means that trainees gain company-specific knowledge regarding the tasks of individual organisational units within particular fields of activity. "Expansion" means the acquisition of know-how that goes beyond the boundaries of departments and indeed of the company as a whole; such knowhow may concern, for instance, external partners (such as contractors or customers; cf. [5, p. 45]). 
- On 2: A positive internal image means enhanced acceptance of TrPr within the organisation and, in particular, stronger support of TrPr on the part of direct superiors, which may at least to some extent mitigate the problem of time shortage discussed earlier. The company's top management is the one circle of individuals that has the power to ensure the long-term existence of $\operatorname{Tr} \operatorname{Pr}$ (cf. [5, p. 53]).

- On 3: A positive external image may in turn help to increase the number and quality of applications for trainee positions, thus creating an advantage for the company (cf. [5, p. 53]). Mentoring in the present context contributes to a partnership between a hierarchically superior person (the mentor) and the hierarchically lower, less experienced trainee. This partnership is in principle one among equals, although the focus of course lies on a learning process on the part of the trainee. Also, the partnership is dynamic in that it will undergo modifications while it lasts. Mentoring must be beneficial to both partners and must rest on mutual trust. Learning from a mentor needs not be restricted to technicalities, but may also include informal personal and power relations; it may facilitate access to networks and thus support the trainee's integration process. Last but not least, the trainee may also learn to assess her or his own performance and potential more accurately. In theory, there is a whole range of objectives of TrPr that might be pursued through a sophisticated mentoring scheme (cf. [5, pp. 81-91]). Firm statistical evidence, however, is only forthcoming for a positive effect on the external image objective. In general, there is still potential for optimisation in this area.

- On 4: Project work can take various forms. Projects may be small and restricted to individual training stages and positions. Less common are larger projects involving informational stays in several organisational departments. Projects are task complexes with limited time resources. They are oriented towards precise goals (adhering to time and cost limits, attaining quality standards, etc.), thus making it possible for $\operatorname{TrPr}$ to have trainees taking considerable responsibility. The objectives of integration and technical education have been mentioned variously. The methodological educational objective comprises, among other things, techniques of information collection and processing and of deriving practical conclusions from such information. More specifically, this involves training in group work and presentation techniques, or methods of project work (e.g. time and cost planning).

- On 5: Intercultural competence is a special variety of social skill. It is the ability to interact with people from foreign cultures in adequate and effective ways. A distinction can be made here between a cognitive level (e.g. linguistic, historical, geographical knowledge), an emotional level (e.g. empathy) and a practical level (communication skills, etc.). As an element in the training of talented young professionals that is continuously growing in importance, intercultural competence is best acquired through stays abroad - provided these are designed such that they actually allow, or indeed enforce, maximally intensive exchanges with the host culture. On 6: In the study under discussion, the sustainability objective was defined in terms of a stay of trainees with the employer for at least three years after completion of the TrPr. Integration of $\operatorname{TrPr}$ within comprehensive HR development schemes is often regarded as more or less a matter of course. For the present study, a special index was developed in order to measure the extent of such integration. The index took the following elements of integration into account: early information on career and further educa- 
tion opportunities after programme completion; continued mentoring after the programme; regular assessment of trainees applying the same system that is used in the company's leadership development programme; integration of trainees in real teams and corporate project groups; personal commitment on the part of the company's top management for the TrPr; and, finally, continued existence of the programme (no termination due to, for instance, cost reasons).

\section{Conclusions and Prospects}

As the present paper should illustrate, a massive amount of know-how relating to $\operatorname{TrPr}$ as a talent management tool has been gathered over the past decades in German-speaking Europe (cf. also [13]). It is an author's heartfelt concern that other regions of Europe and the world should benefit from these rich resources of knowledge and experience.

Progress in empirical research has made it possible to evaluate actual programmes with regard to their effectiveness and efficiency. The author's research institute at the University of Berne has twice awarded a prize for the best TrPr in Switzerland; the relevant catalogue of criteria has been published (cf. [10, pp. 31ff.]). The results of evaluations at various companies make it clear that at least the leading employers are very skilled at using $\operatorname{TrPr}$ as a talent management instrument. This, together with the overview of academic research provided in the sections above, will hopefully convince the reader of the truth of the claim made at the beginning of this paper that the outcome of the BCG/WFPMA study according to which there is an imbalance between "future importance" and "current capability" in the area of talent management is too sweeping in the light of what has been and is still achieved with TrPr for graduates in German-speaking Europe. What remains to be made at this point are a number of concluding remarks on the pedagogical role of $\operatorname{TrPr}$ and their place in the broader educational and economic context:

1- University graduates, particularly those in business administration and economics, tend to be capable, but not quite ready yet for entering the profession. Tailor-made forms of supplementary training at and by employers are required. In a sense, a $\operatorname{TrPr}$ is a dual educational programme where theory-centred university courses are followed by more strictly regimented corporate training.

2- In German-speaking Europe, TrPr have in the meantime been opened to graduates from so-called universities of applied sciences (UAS), i.e. institutions of higher education for people who have first completed an apprenticeship. On graduation from an UAS, usually with a bachelor degree, the great majority of students enter working life. It is also possible, however, to go on studying for a master's degree, either at the UAS or at regular universities, which usually demands successful passing of further exams before accepting UAS students. Such additional requirements notwithstanding "permeability" are a cherished ideal in this system: young people need not go straight to university; they can do an apprenticeship first, after which they still have all options open to themselves. There is thus no need for a high percentage of an age-group to strive directly for tertiary education through one or another kind of purely theoretical university admission qualification (as is the case with most countries outside German-speaking Europe). As a rule, employability is considerably improved where such alternative educational paths exist. There is a reason to assume a causal link here with the relatively low youth unemployment numbers in German-speaking Europe. 
3- Currently, there are developments towards "dual study programmes": university students are formally employed by companies while studying for a bachelor or master's degree, where the academic courses include project and transfer work to additionally increase practical relevance. Steinbeis University Berlin/Germany is one example of the institution that has been collecting a lot of experience with this kind of scheme and cooperates with renowned employers such as Daimler or Bosch.

4- The German-speaking countries are very much export-oriented and are home to many international companies. Accordingly, stays abroad, as an integral part of TrPr, have grown in importance in recent decades. Doing part of participants' trainee programmes in foreign subsidiaries, not only improves their intercultural competence, but it may also contribute to corporate know-how export, thus enabling companies to benefit far beyond the immediate purposes of an established tool for fostering and managing talent. 


\section{References}

- Boston Consulting Group, World Federation of Personnel Management Associations (BCG, WFPMA). (2010). Creating People Advantage 2010: How companies can adapt their HR practices for volatile times, published online, https://www.bcgperspectives.com/content/articles/organization_transformation_creating_people_advantage_2010/.

- Becker, M. (2013). Personalentwicklung. $6^{\text {th }}$ ed., Stuttgart.

- Boston Consulting Group, World Federation of Personnel Management Associations (BCG, WFPMA). (2011). Creating People Advantage 2011: Time to act: HR certainties in uncertain times, published online, https://www.bcgperspectives.com/content/articles/people_management_human_ resources_creating_people_advantage_2011/.

- Jäger, W. (2009). "Talentmanagement ist Personalmanagement", in: W. Jäger and A. Lukasczyk (eds.) Talent Management. Köln, pp. 15-24.

- Nesemann, K. (2012). Talentmanagement Durch Trainee-Programme: Talent Management by Means of Trainee Programmes. Wiesbaden.

- $\quad$ Ritz, A. and N. Thom (eds.). (2011). Talent Management. $2^{\text {nd }}$ ed., Wiesbaden.

- Strack, R. (2011). Certainties in Uncertain Times, "Personalwirtschaft" Sonderheft 1, pp. 1417.

- Thom, N. (1987). Personalentwicklung als Instrument der Unternehmungsführung. Stuttgart.

- Thom, N. and K. Nesemann. (2011). “Talententwicklung durch Trainee-Programme“, in: A. Ritz and N. Thom (eds.) Talent Management. pp. 25-38.

- $\quad$ Thom, N. and A. Ritz. (2008). Public Management. $4^{\text {th }}$ ed., Wiesbaden.

- Thom, N. and A. Ritz. (2013). Management Public. Lausanne.

- $\quad$ Thom, N. and V. Friedli. (2008). Hochschulabsolventen Gewinnen: Fördern und Erhalten. $4^{\text {th }}$ ed., Bern.

- Wegerich, C. (2013). Handbuch Traineeprogramme. Stuttgart. 